Article

\title{
Astemizole Sensitizes Adrenocortical Carcinoma Cells to Doxorubicin by Inhibiting Patched Drug Efflux Activity
}

\author{
Anida Hasanovic, Méliné Simsir, Frank S. Choveau, Enzo Lalli and Isabelle Mus-Veteau * \\ Université Côte d'Azur, CNRS, Institut de Pharmacologie Moléculaire et Cellulaire, 06560 Valbonne, France; \\ anida160@hotmail.com (A.H.); simsir@ipmc.cnrs.fr (M.S.); choveaufrank@gmail.com (F.S.C.); \\ lalli@ipmc.cnrs.fr (E.L.) \\ * Correspondence: mus-veteau@ipmc.cnrs.fr
}

Received: 17 June 2020; Accepted: 24 July 2020; Published: 29 July 2020

check for updates

\begin{abstract}
Adrenocortical carcinoma (ACC) presents a high risk of relapse and metastases with outcomes not improving despite extensive research and new targeted therapies. We recently showed that the Hedgehog receptor Patched is expressed in ACC, where it strongly contributes to doxorubicin efflux and treatment resistance. Here, we report the identification of a new inhibitor of Patched drug efflux, the anti-histaminergic drug astemizole. We show that astemizole enhances the cytotoxic, proapoptotic, antiproliferative and anticlonogenic effects of doxorubicin on ACC cells at concentrations of astemizole or doxorubicin that are not effective by themselves. Our results suggest that a low concentration of astemizole sensitizes ACC cells to doxorubicin, which is a component of the standard treatment for ACC composed of etoposide, doxorubicin, cisplatin and mitotane (EDPM). Patched uses the proton motive force to efflux drugs. This makes its function specific to cancer cells, thereby avoiding toxicity issues that are commonly observed with inhibitors of $A B C$ multidrug transporters. Our data provide strong evidence that the use of astemizole or a derivative in combination with EDPM could be a promising therapeutic option for ACC by increasing the treatment effectiveness at lower doses of EDPM, which would reduce the severe side effects of this regimen.
\end{abstract}

Keywords: adrenocortical carcinoma; Patched; drug efflux pump; chemotherapy resistance; small lead molecule; repositioning; cancer therapy

\section{Introduction}

Adrenocortical carcinoma (ACC) is a rare endocrine malignancy with an annual incidence of $0.5-2$ cases per million people per year [1,2]. The prognosis of ACC is overall poor, particularly with cortisol-producing tumors [3]. Complete tumor removal by surgery is the most important step in the management of patients with primary, recurrent or metastatic ACC. However, $40-50 \%$ of patients who underwent surgery have a survival rate of about five years [4]. The main reason for that is the advanced stage of the disease at the moment of diagnosis, which makes impossible the complete removal of the tumor with surgery, and relapse appears in approximately $70-80 \%$ of patients after resection. ACC patients present a high risk of relapse and metastases even when the primary tumor is diagnosed and surgically excised at an early stage. Outcomes did not improve despite extensive research [5]. Mitotane and etoposide/doxorubicin/cisplatin chemotherapy have been validated for improved recurrence-free survival of patients with ACC [6]. However, a minority of patients experience a sustained benefit of this regimen which presents side effects so severe that often makes the patients unable to attain target drug doses shown to give a survival benefit $[7,8]$. Five-year survival rates of $35 \%$ in advanced ACC suggest that resistance to adjuvant therapy is the main factor behind treatment 
failure [9]. Therefore, it is necessary to find new therapeutic options to improve ACC treatment outcomes and increase the overall survival of patients.

It has long been postulated that the multidrug $A B C$ transporter P-glycoprotein (P-gp/ABCB1/MDR1) mediates the main mechanism of resistance within cancer cells [10]. However, we recently showed that the Hedgehog receptor Patched (Ptch1), which is overexpressed in many recurrent and metastatic cancers ([11,12], and Human Protein Atlas website http://www.proteinatlas. org/ENSG00000185920-PTCH1/cancer), is also expressed in ACC and contributes to resistance of ACC to treatment [13]. Indeed, Ptch1 pumps chemotherapeutic agents such as doxorubicin (dxr) out of cancer cells, leading to chemotherapy resistance $[13,14]$. Ptch1 is not part of the ABC transporters family but uses the proton motive force to efflux drugs similar to the bacterial efflux pumps from the RND family [15]. This may seem surprising; however, the high glucose utilization and the alteration of energy metabolism that occur in cancer cells have been shown to lead to lactate production which is transported out of the cells and acidifies the extracellular medium [16]. This pattern of the acidic extracellular environment and alkaline cytosol is considered as a hallmark of malignant cancers and is referred to as a "reversed $\mathrm{pH}$ gradient" [17]. Accordingly, Ptch1 functions as an efflux pump only in cancer cells. This makes Ptch1 a particularly relevant therapeutic target, and Ptch1 drug efflux inhibitors particularly interesting due to their specificity for cancer cells.

We developed screening tests to identify molecules that inhibit the resistance to doxorubicin (dxr), a chemotherapeutic agent used to treat many cancers, conferred by human Ptch1 to yeast, and the efflux of dxr by Ptch1 [18]. This led to the discovery of two Ptch1 inhibitors. The first, panicein A hydroquinone (PAH), a compound purified from a marine sponge, increased the cytotoxicity of $d x r$ against melanoma cells in vitro and in vivo $[19,20]$. The second inhibitor, methiothepin, a drug-like compound from the Prestwick Chemical library, increased the efficacy of $\mathrm{dxr}$ against adrenocortical carcinoma cells in vitro and in vivo [13]. When screening the Prestwick Chemical library, we identified a second compound able to inhibit the resistance to $\mathrm{dxr}$ conferred by Ptch1 to yeast and the efflux of $\mathrm{dxr}$ mediated by Ptch1. This compound is astemizole, a non-sedating anti-histaminergic drug. In the present study, we report results showing that astemizole is a Ptch1 drug efflux inhibitor and the effects of this compound on the response of ACC cells to doxorubicin.

\section{Materials and Methods}

\subsection{Chemical and Biological Material}

Astemizole was purchased from Santa Cruz: CAS number: 68844-77-9; MW: $458.57 \mathrm{~g} / \mathrm{mol}$; molecular formula: $\mathrm{C}_{28} \mathrm{H}_{31} \mathrm{FN}_{4} \mathrm{O}$. Doxorubicin hydrochloride was purchased from Sigma-Aldrich. BODIPY-cholesterol was purchased from Avanti (Topfluor, Avanti Polar Lipids Inc, Alabaster, AL, USA).

Saccharomyces cerevisiae strain K699 (Mata, ura3 and leu 2-3, kindly donated by R. Arkowitz) was transformed with the expression vectors pYEP-hPtc-MAP (human Ptch1) or pYEP-hSmo-MAP (control), and grown at $18{ }^{\circ} \mathrm{C}$ until $\mathrm{OD}_{600} 5-7$ as previously described [20].

The human adrenocortical carcinoma cell line H295R was grown in DMEM/F12 medium containing $2 \%$ NuSerum (BD), $1 \%$ ITS + (BD) and penicillin/streptomycin (Invitrogen, Thermo Fisher Scientific, Illkirch, France) at $37^{\circ} \mathrm{C}$ and $5 \% \mathrm{CO}_{2}$ as previously described [13]. This medium was supplemented with $20 \mu \mathrm{g} / \mu \mathrm{L}$ EGF and $20 \mu \mathrm{g} / \mu \mathrm{L}$ FGF for spheroid 3D culture.

Human embryonic kidney cells HEK293 were grown in DMEM medium (Gibco, Thermo Fisher Scientific, Illkirch, France) supplemented with $10 \%$ fetal calf serum (Thermo Fisher Scientific, Illkirch, France) and 1\% penicillin-streptomycin (Gibco, Thermo Fisher Scientific, Illkirch, France) at $37^{\circ} \mathrm{C}$ in $5 \% \mathrm{CO}_{2}$ water-saturated atmosphere.

\subsection{Screening on the Resistance to Doxorubicin of Yeast Expressing Human Ptch1}

The screening of molecules on yeast was carried out as described in [18]. Briefly, S. cerevisiae expressing human Ptch 1 were grown at $30{ }^{\circ} \mathrm{C}$ up to an $\mathrm{OD}_{600}$ between 1 and 2 in minimal medium 
containing $2 \%$ of glucose and amino acid cocktail without leucine, and then diluted in rich medium containing $2 \%$ glucose in $96-$ well plates. An amount of $10 \mu \mathrm{M}$ of molecules to be tested was added in 8 wells ( 10 molecules can be tested on one plate) and $10 \mu \mathrm{M}$ of $\mathrm{dxr}$ was added to half of the wells. Plates were incubated at $18{ }^{\circ} \mathrm{C}$ on a shaker at $1250 \mathrm{rpm}$ (microtiter plate shaker SSL5 Stuart) and absorbance at $600 \mathrm{~nm}$ was recorded for about $72 \mathrm{~h}$.

\subsection{Cytotoxicity Assays}

Cytotoxicity assays on H295R cells were carried out as previously described [13]. Briefly, H295R cells were grown in 96-well plates to achieve $70 \%$ to $80 \%$ confluence. The medium was then replaced with $100 \mu \mathrm{L} /$ well of medium containing astemizole or DMSO as control for $2 \mathrm{~h}$. An amount of $100 \mu \mathrm{L}$ of medium containing increasing concentrations of $\mathrm{dxr}$ was then added. For astemizole $\mathrm{IC}_{50}$ calculation, cells were incubated with increasing concentrations of astemizole. Plates were incubated at $37{ }^{\circ} \mathrm{C}$ and $5 \% \mathrm{CO}_{2}$. After $48 \mathrm{~h}$, cells were incubated $3 \mathrm{~h}$ at $37^{\circ} \mathrm{C}$ with neutral red (NR) solution following the manufacturer's protocol. Absorbance was measured in a microplate reader (Multiskan Go Microplate Spectrophotometer from Thermo Fisher Scientific, Illkirch, France). IC $_{50}$ corresponding to the concentration of $\mathrm{dxr}$ or astemizole that induced a $50 \%$ decrease in the number of live cells was calculated using the GraphPad Prism 6 software.

\subsection{Synergy Analysis of Drug Combination}

Synergy analysis was performed using the Chou-Talalay method for drug combination as described in [21,22]. Analysis was done on the basis of dose-response curves of cells treated for $48 \mathrm{~h}$ with $\mathrm{dxr}$ alone, astemizole alone and $\mathrm{dxr}$ in the presence of $1 \mu \mathrm{M}$ astemizole. Normalized isobolograms and Chou-Talalay's plots (Fa-CI plot were Fa is the fraction affected and CI is the combination index) were created using the Compusyn Software (Version 1.0 downloaded from www.combosyn.com [22]). These allow quantitative determination of drug interactions, where $\mathrm{CI}<1$ (below the diagonal), =1 (diagonal) and $>1$ (above the diagonal) indicate synergism, additive effect and antagonism, respectively. Dose-reduction index (DRI) is reported.

\subsection{Apoptosis Measurements}

Cells were seeded at a density of 7000 cells per well in a 96-well white polystyrene plate (Falcon Corning 96 Well Plate) in triplicate and cultured overnight at $37^{\circ} \mathrm{C}$ and $5 \% \mathrm{CO}_{2}$. After removal of the medium, cells were treated $48 \mathrm{~h}$ with medium containing DMSO, $\mathrm{dxr}$ alone, astemizole alone or $\mathrm{dxr}$ and astemizole together. Quantification of caspase 3/7 activity was performed using the luminescent assay Caspase-Glo 3/7 (Promega, Charbonnières-les-Bains, France) and a luminometer (Glomax 96 Microplate Luminometer from Promega, Charbonnières-les-Bains, France) following the manufacturer's protocol.

\subsection{Proliferation}

Cells were seeded at a density of 5000 cells per well in 96-well plates (Falcon 96 Well Clear Microplate, Corning Inc, Corning, NY, USA) in triplicate and grown for $24 \mathrm{~h}$ at $37{ }^{\circ} \mathrm{C}$ and $5 \% \mathrm{CO}_{2}$. After removal of the medium, cells were treated with medium containing serial dilutions of $\mathrm{dxr}$ in the presence or the absence of astemizole. DMSO was added to the control wells. After 7 days at $37^{\circ} \mathrm{C}$ and $5 \% \mathrm{CO}_{2}$, the NR test was used for the quantification of living cells. $\mathrm{IC}_{50}$ values were calculated using the GraphPad Prism 6 software.

\subsection{Clone Formation}

Effect of astemizole on $\mathrm{H} 295 \mathrm{R}$ clone formation was carried out as previously described [13]. A total of 5000 H295R cells were seeded per well in 24-well plates (Falcon from Corning Inc, Corning, NY, USA), treated in triplicate with DMSO as control, astemizole alone, $\mathrm{dxr}$ alone or a combination of astemizole and $\mathrm{dxr}$, and incubated at $37^{\circ} \mathrm{C}$ and $5 \% \mathrm{CO}_{2}$. After 14 days, clones were stained with crystal violet and 
pictures were taken. Cells were then solubilized and absorbance was measured in a microplate reader at $550 \mathrm{~nm}$ (Multiskan Go Microplate Spectrophotometer, Thermo Scientific, Illkirch, France).

\subsection{Spheroid Formation in 3D Culture}

H295R cells were cultured in DMEM/F-12, 2\% NuSerum, 1\% ITS Plus and penicillin/streptomycin supplemented with $20 \mu \mathrm{g} / \mu \mathrm{L}$ EGF and $20 \mu \mathrm{g} / \mu \mathrm{L}$ FGF. Cells were seeded in 96-well plates (Falcon from Corning Inc, Corning, NY, USA) at a density of 5000 cells per well in triplicate, treated with DMSO as control, astemizole alone, $\mathrm{dxr}$ alone or a combination of astemizole and $\mathrm{dxr}$, and incubated at $37^{\circ} \mathrm{C}$ and $5 \% \mathrm{CO}_{2}$. After 14 days, images of each well were taken using a cell imaging multi-mode reader (Cytation 5 from Bio Tek, Colmar, France). Then, $100 \mu \mathrm{L}$ of the medium was removed from each well and $100 \mu \mathrm{L}$ of Cell Titer Glow 3D reagent (Promega) was added. Spheroids were disrupted according to the protocol from the Cell Titer Glow 3D Viability Assay (Promega) and viability was measured in a microplate reader at $550 \mathrm{~nm}$ (Multiskan Go Microplate Spectrophotometer, Thermo Scientific).

\subsection{SDS-PAGE and Western Blotting}

Western blots were carried out as previously described [13]. Total RIPA extracts from cells were prepared and protein concentration was estimated using the DC Protein Assay (Bio-Rad, Feldkirchen, Germany). An amount of 50 to $80 \mu \mathrm{g}$ of proteins was separated on SDS-PAGE and transferred to membranes of nitrocellulose (Amersham, Bath, UK). After $1 \mathrm{~h}$ blocking in $5 \%$ non-fat milk, membranes were incubated overnight at $4{ }^{\circ} \mathrm{C}$ with rabbit anti-hPtch1 antibody (Abcam ab53715; 1/1000) or mouse anti- $\beta$-tubulin antibody (Sigma Aldrich, Merck, Darmstadt, Germany; $1 / 1000$ ). After washing, membranes were incubated for $45 \mathrm{~min}$ with anti-rabbit (1:2000) or anti-mouse (1:5000) immunoglobulin coupled to horseradish peroxidase (Dako-Agilent, Santa Clara, CA, USA). ECL Prime Western Blotting detection reagent (Amersham) on a Fusion FX imager (Vilber Lourmat, Collegien, France) was used for detection.

\subsection{Efflux Measurements}

Efflux measurements were carried out as described in [19]. On yeast: hPtch1-expressing yeasts or control yeasts were grown to an $\mathrm{OD}_{600}$ of 5 , centrifuged, washed with cold water and resuspended in HEPES-NaOH buffer (pH 7.0) containing $5 \mathrm{mM}$ 2-deoxy-D-glucose and $10 \mu \mathrm{M} \mathrm{dxr}$ for $2 \mathrm{~h}$ at $4{ }^{\circ} \mathrm{C}$. After centrifugation, one sample was immediately fixed with $4 \%$ PFA for dxr loading control, while the other samples were resuspended in HEPES-NaOH buffer ( $\mathrm{pH}$ 7.0) containing $5 \mathrm{mM}$ 2-deoxy-D-glucose and DMSO or $10 \mu \mathrm{M}$ astemizole, and incubated $10 \mathrm{~min}$ at $20^{\circ} \mathrm{C}$ with gentle shaking in a Benchmark Multi-therm shaker (Innova 2000, New Brunswick Scientific, Enfield, CT, US) protected from light. Yeasts were centrifuged, resuspended in $4 \%$ PFA and deposited on a coverslip with SlowFade Gold antifade reagent containing DAPI (Invitrogen).

On cells: After seeding on coverslips in 24 -well plates, $\mathrm{H} 295 \mathrm{R}$ cells were incubated at $37^{\circ} \mathrm{C}$ and $5 \%$ $\mathrm{CO} 2$ with $10 \mu \mathrm{M}$ doxorubicin (dxr) or BODIPY-cholesterol (Bo-chol) in physiological buffer $(140 \mathrm{mM}$ $\mathrm{NaCl}, 5 \mathrm{mM} \mathrm{KCl}, 1 \mathrm{mM} \mathrm{CaCl}, 1 \mathrm{mM} \mathrm{MgSO} \mathrm{m}_{4}, 5 \mathrm{mM}$ glucose, $20 \mathrm{mM}$ HEPES, pH 7.4). After $2 \mathrm{~h}$, some coverslips were immediately fixed with PFA and mounted in SlowFade Gold antifade reagent containing DAPI (Invitrogen) for loading control. The other coverslips (a triplicate per condition) were incubated with physiological buffer containing DMSO or $10 \mu \mathrm{M}$ astemizole for 30 min under gentle shaking at room temperature and protected from light, fixed with PFA and mounted as described above.

Images were acquired with a Zeiss Axioplan 2 fluorescence microscope coupled to a digital charge-coupled device camera using a 63X objective for yeast or a 40X /1.3 Plan NeoFluar objective for cells, and filters for Alexa 594 or FITC for dxr or Bo-chol analysis, respectively. Dxr or Bo-chol fluorescence was quantified using the ImageJ software. About 100 yeast/cells (from three wells) were scored per condition. 


\subsection{Electrophysiology}

Transfection and experiments were carried out as described in [23]. HEK293 cells were plated onto $35 \mathrm{~mm}$ dishes for transfection with pSI-hERG, and experiments were performed over the following 1-2 days. In the standard bath solution, pulled pipettes had resistances of 2-4 M $\Omega$ when filled with intracellular solution containing $74.5 \mathrm{mM} \mathrm{KCl}, 70.5 \mathrm{mM}$ K-aspartate, $5 \mathrm{mM}$ HEPES, $2 \mathrm{mM}$ EGTA, $2 \mathrm{mM}$ $\mathrm{K}_{2} \mathrm{ATP}$ and $0.3 \mathrm{mM} \mathrm{MgCl} 2 \mathrm{pH} 7.2$ with $\mathrm{KOH}$. Whole-cell membrane currents were measured and filtered at $3 \mathrm{kHz}$ using a patch-clamp amplifier RK 400 (Bio-Logic Science Instruments, Seyssinet-Pariset, France), digitized at $10 \mathrm{kHz}$ with the 12-bit analog-to-digital converter Digidata-1322 (Axon Instrument, Sunnyvale, CA, United States) and recorded with the software Clampex 8.2 (Axon Instrument). hERG currents in HEK cells were recorded using an external solution composed of: $145 \mathrm{mM} \mathrm{NaCl}, 4 \mathrm{mM}$ $\mathrm{KCl}, 1 \mathrm{mM} \mathrm{MgCl}$, $1 \mathrm{mM} \mathrm{CaCl}_{2}, 5 \mathrm{mM}$ HEPES and $5 \mathrm{mM}$ glucose, $\mathrm{pH}$ adjusted to 7.4 with $\mathrm{NaOH}$ and flowed at $1-2 \mathrm{~mL} / \mathrm{min}$ through the dish. Astemizole was dissolved in DMSO to produce a 50-mM stock solution stored at $-20^{\circ} \mathrm{C}$. The final experimental concentration was reached by dilution in the locally perfused external medium described above. Experiments were performed at room temperature.

\subsection{In Silico Docking}

Docking of astemizole on the Ptch1 structure was performed using the Vina toolkit [24] in USCF Chimera [25] as previously described [20]. The structure of Ptch1 (PDB ID: 6N7H, chain A) [26] was prepared using USCF Chimera Predock Toolkit, the Dunbrack rotamer 2010 library [27] for the missing side chains and ANTECHAMBER Amber ff14SB force field [28] for charges assignment. The docking was done by targeting the central cholesterol cavity. The 10 best poses of the docking (ranked by score) were used for the analysis. Interactions were analyzed using PoseView [29], a function of the ProteinsPlus web server [30]. Amino acids within a radius of $6 \AA$ from astemizole were selected and compared to amino acids within a radius of $6 \AA$ from cholesterol.

Sequence alignment was performed on 30 sequences from Patched family members using the T-COFFEE server for transmembrane proteins [31] to identify conserved amino acids.

\subsection{Profiling and Pharmacokinetic Studies}

Profiling and PK studies were performed by GalenAuxi Co (Oxford, UK) as previously described [13]. Astemizole was formulated in DMSO/Solutol ${ }^{\circledR}$ HS15/ PBS and administered to non-fasted male ICR mice (weighing 20-30 g) intravenously (IV) at the dosing volume of $5 \mathrm{~mL} / \mathrm{kg}$ and orally (PO) at $10 \mathrm{~mL} / \mathrm{kg}, 3$ mice per time point. Plasma samples $(50 \mu \mathrm{L})$ were collected via the facial vein at 3, 10, 30, 60, 120, 240, 360 and 1440 min post-dose for the IV group, and at 10, 30, 60, 120, 240, 360, 480 and 1440 min post-dose for the PO group in $K_{2}$ EDTA-coated tubes, mixed gently and centrifuged at $2500 \mathrm{~g}$ for $15 \mathrm{~min}$ at $4{ }^{\circ} \mathrm{C}$ within $1 \mathrm{~h}$ after collection. For control animals, blood was collected by cardiac puncture. Plasma samples were prepared in acetonitrile for LC-MS/MS analysis. Peak areas were recorded and the concentrations of the test compound in the unknown plasma samples were determined using the respective calibration curve. Plasma concentration-time curves were constructed and pharmacokinetic parameters of astemizole were obtained from the analysis of the plasma data.

\subsection{Statistical Analysis}

All results presented were obtained from at least three independent experiments, and data are given as the mean value \pm SEM. The GraphPad Prism 6 software (San Diego, CA, US) was used for statistical analyses with one-way analysis of variance (ANOVA) followed by Bonferroni's multiple comparison tests. 


\section{Results}

3.1. Identification of a New Inhibitor of the Resistance to Doxorubicin and the Doxorubicin Efflux Conferred by Ptch1 to Yeast

We previously reported that yeast expressing human Patched (hPtch1) were able to grow in the presence of chemotherapeutic agents such as doxorubicin (dxr) and to efflux dxr out of cells using the proton motive force [14]. To find inhibitors of Patched drug efflux activity, we developed a screening test based on the growth of hPtch1-expressing yeast in the presence of $d x r$ [18]. We measured the effect of 1200 compounds from the Prestwick Chemical drug library on the growth of hPtch1-expressing yeast in the presence of $d x r$, and we discovered that the methiothepin maleate (P375) significantly inhibited the resistance of hPtch1-expressing yeast to $\mathrm{dxr}$ in contrast to the other compounds such as P298 that did not affect it (Figure 1A). During this screening, we observed that another drug from the same library, P136, was also able to inhibit the growth of hPtch1-expressing yeast in the presence of $d x r$ without effects on the growth of hPtch1-expressing yeast in the absence of $d x r$ (Figure 1A), suggesting that this molecule inhibited specifically $\mathrm{dxr}$ resistance conferred by hPtch1 to yeast.

\section{A}
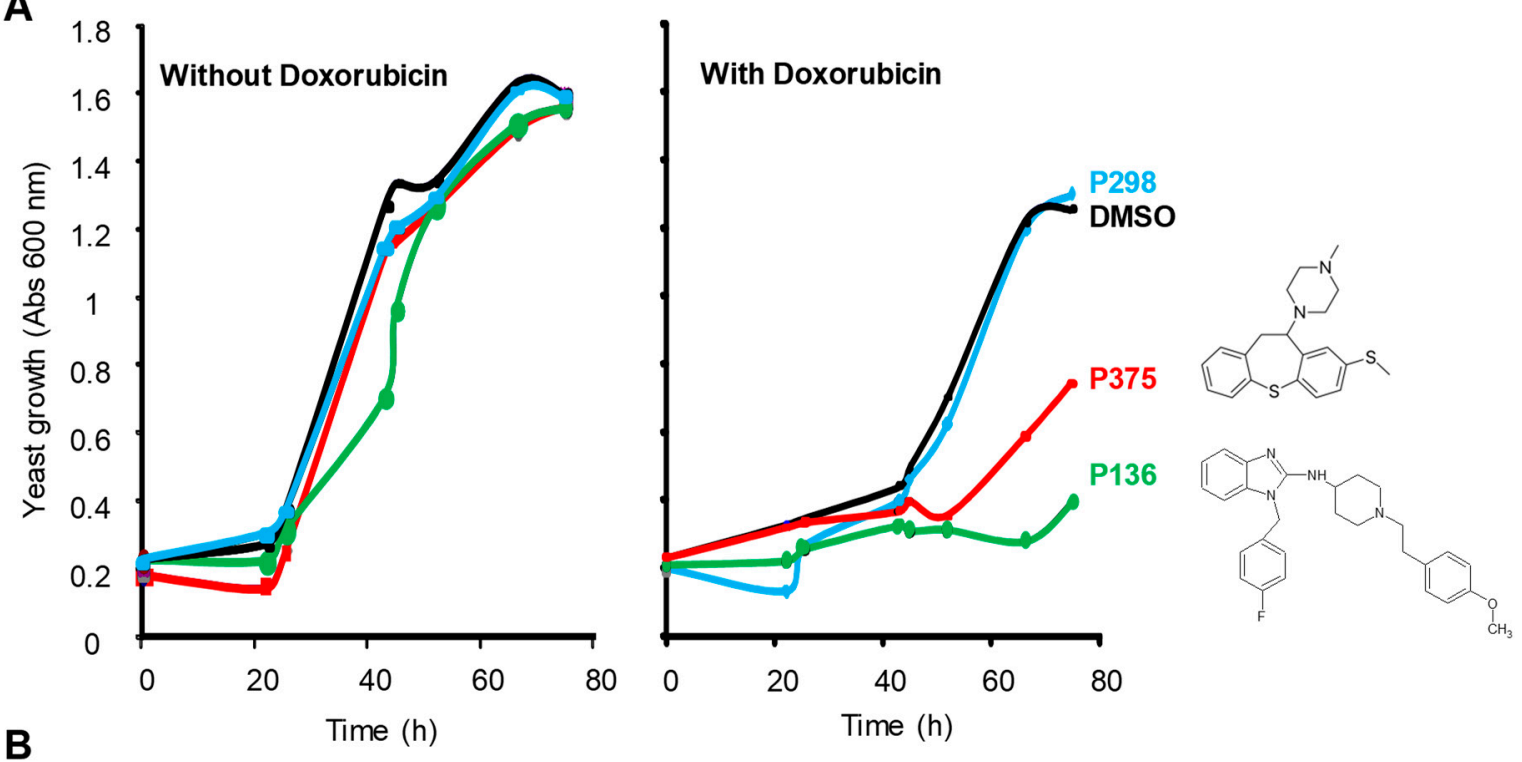

B
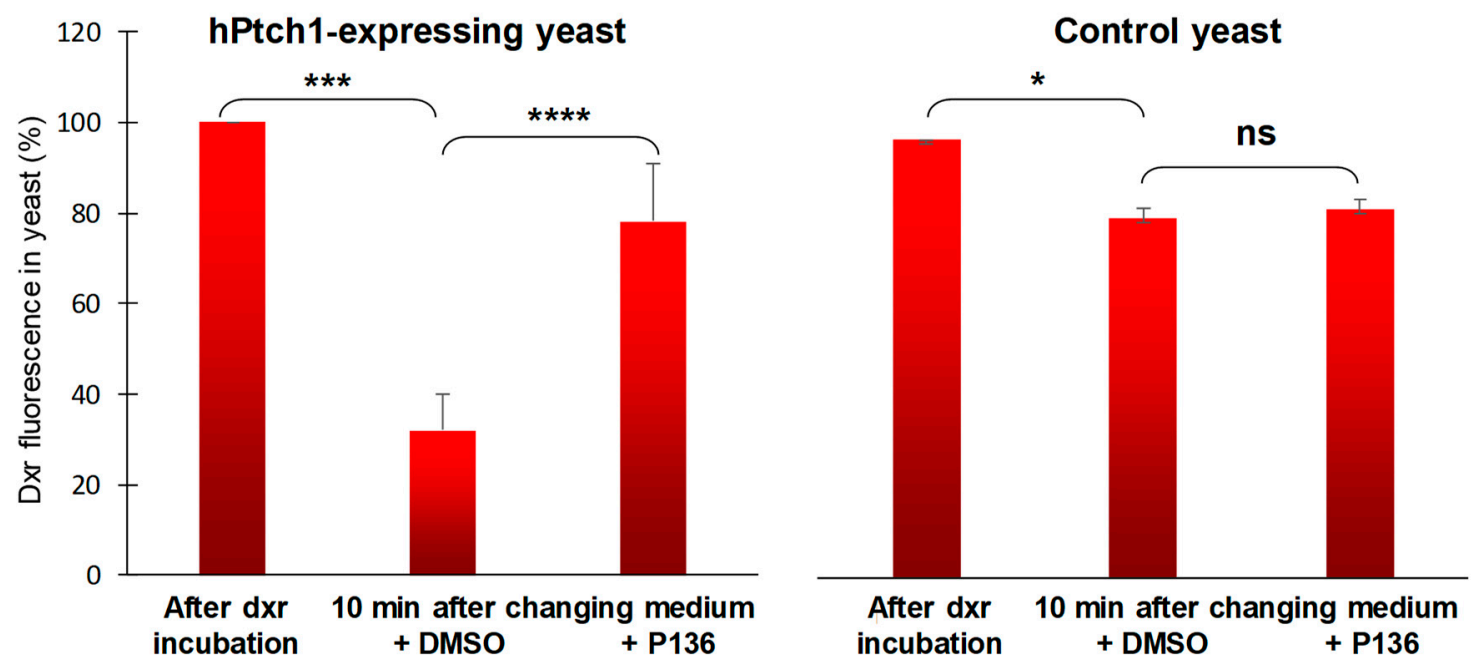

Figure 1. P136 inhibits doxorubicin efflux activity of hPtch1 when expressed in yeast. (A) P136 inhibits the resistance of hPtch1-expressing yeast to doxorubicin. hPtch1-expressing yeast were grown in the presence of $10 \mu \mathrm{M}$ of P136, P298 or P375, and in the presence or absence of $10 \mu \mathrm{M}$ doxorubicin $(\mathrm{dxr})$. 
DMSO was used as control. The growth of yeast was measured by absorbance at $600 \mathrm{~nm}$. (B) P136 inhibits the efflux of doxorubicin of hPtch1-expressing yeast. hPtch1-expressing yeast and control yeast were incubated with $\mathrm{dxr}$ for $2 \mathrm{~h}$ and fixed for $\mathrm{dxr}$ loading control or resuspended in buffer containing DMSO or $10 \mu \mathrm{M}$ P136 for $10 \mathrm{~min}$, fixed and deposited on a coverslip for analysis by fluorescence microscopy. The $\mathrm{dxr}$ fluorescence of 100 yeast for each condition from 3 independent experiments was quantified using the ImageJ software. Histograms represent the mean \pm SEM and were analyzed using ANOVA multiple comparison test and Bonferroni correction. Significance is attained at $p<0.05\left(^{*}\right)$ $\left(^{* * *}: p<0.0005,{ }^{* * * *}: p<0.00005\right.$, ns: no significant difference).

Then, we measured the effect of P136 on the amount of dxr in hPtch1-expressing yeast by fluorescence microscopy using the natural fluorescence of $d x r$ as described before [19]. Experiments were performed in the presence of 2-deoxy-D-glucose to inhibit ATP production and thus the contribution of yeast MDR transporters from the ATP-binding cassette (ABC) to the drx efflux. This allowed us to better visualize Ptch1's contribution to the dxr efflux because Patched does not use ATP hydrolysis but rather the proton motive force to get the drugs out of the cells. After incubation with $d x r$, we observed that $d x r$ accumulated in yeast. After removing the medium containing $d x r$ and 10 min in buffer containing DMSO (P136 solvent), hPtch1-expressing yeasts contain significantly less $\mathrm{dxr}$ fluorescence than control yeasts, consistently with the dxr efflux activity of hPtch1 previously reported [14] (Figure 1B). Remarkably, the presence of P136 in the efflux buffer increases the amount of $\mathrm{dxr}$ in hPtch1-expressing yeast significantly more than in control yeast (Figure 1B), indicating that P136 specifically inhibited dxr efflux activity mediated by hPtch1.

Compound P136 corresponds to astemizole, a well-known non-sedating second-generation $\mathrm{H}_{1}$-histamine receptor antagonist.

\subsection{Astemizole Increases the Cytotoxicity of ACC Standard Treatment}

We recently showed that ACC expresses Ptch1 and that the first Ptch1 drug efflux inhibitor identified from our screening of the Prestwick Chemical library, methiothepin, was able to increase the efficacy of doxorubicin against the human ACC cell line H295R [13]. Therefore, we wanted to know if astemizole was also able to increase dxr efficacy against ACC cells. H295R cells were grown to 80\% confluence and incubated with increasing concentrations of $\mathrm{dxr}$ in the absence or the presence of $1 \mu \mathrm{M}$ astemizole for $48 \mathrm{~h}$. The cell viability assay using neutral red revealed that a dose of $1 \mu \mathrm{M}$ astemizole, that was not toxic to ACC cells by itself, increased the cytotoxicity of $\mathrm{dxr}$ by about 10 times (Figure 2A, Table 1). The gold standard treatment given to ACC patients is composed of a mixture of doxorubicin, etoposide, cisplatin and mitotane (EDPM). Interestingly, we observed that astemizole increased about eight times the efficacy of $\mathrm{dxr}$ when combined with $10 \mu \mathrm{M}$ etoposide and $10 \mu \mathrm{M}$ mitotane (EDM) (Figure 2B, Table 1).

Table 1. Astemizole increases the cytotoxicity of chemotherapeutic treatments on adrenocortical carcinoma (ACC) cells. Cell viability was measured after $48 \mathrm{~h}$ of treatment of H295R cells with serial dilutions of doxorubicin ( $\mathrm{dxr}$ ) alone or in combination with $10 \mu \mathrm{M}$ mitotane and $10 \mu \mathrm{M}$ etoposide (EDM) in the presence or the absence of $1 \mu \mathrm{M}$ astemizole. $\mathrm{IC}_{50}$ values of $\mathrm{dxr}$ reported are the mean $\pm \mathrm{SEM}$ of 3 independent experiments.

\begin{tabular}{ccc}
\hline & \multicolumn{2}{c}{ Dxr-IC $_{50}(\mu \mathrm{M})$} \\
\hline Treatment & Without Astemizole & With Astemizole \\
\hline Dxr & $17.3 \pm 3.6$ & $1.65 \pm 0.4$ \\
EDM & $15.93 \pm 4$ & $1.84 \pm 0.7$ \\
\hline
\end{tabular}

The Chou-Talalay's plot (Fa-CI plot) and normalized isobologram analysis clearly showed that $\mathrm{dxr}$ and astemizole exhibit a significant synergism as demonstrated by the cooperativity indices $(\mathrm{CI})$ 
far below 1 (Figure S1A). Similar results were obtained for the combination of astemizole with EDM treatment (Figure S1B).

Western blot analysis and quantification of the Ptch1 protein amount relative to $\beta$-tubulin revealed that astemizole treatment did not affect Ptch1 protein expression (Figure 2C).
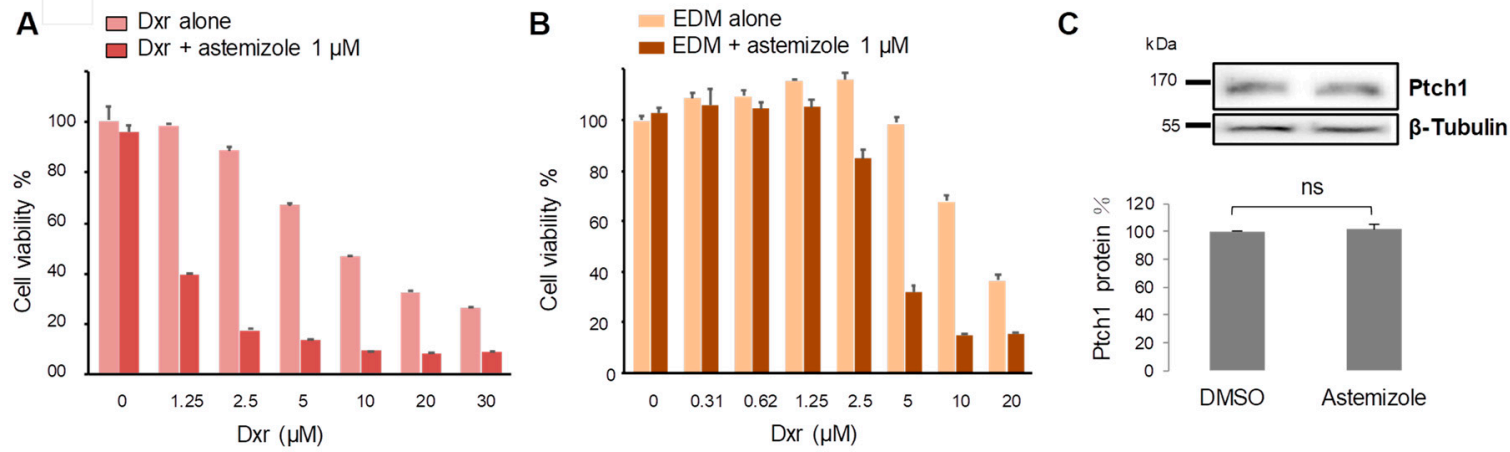

Figure 2. Astemizole increases the cytotoxic effect of ACC treatment. Cell viability was measured after $48 \mathrm{~h}$ treatment of H295R cells with serial dilutions of doxorubicin (dxr) (A) in the presence or the absence of $1 \mu \mathrm{M}$ astemizole, (B) in the presence of $10 \mu \mathrm{M}$ mitotane and $10 \mu \mathrm{M}$ etoposide with or without $1 \mu \mathrm{M}$ astemizole. The graphs reported are representative of more than 3 independent experiments. (C) Ptch1 protein expression after $48 \mathrm{~h}$ of treatment with $10 \mu \mathrm{M}$ astemizole or DMSO as control. Quantification of Ptch1 expression level relative to $\beta$-tubulin was performed using the ImageJ software on 3 independent experiments. ns: no significant difference.

\subsection{Astemizole Increases the Pro-Apoptotic, Anti-Proliferative and Anti-Clonogenic Effects of Doxorubicin}

We observed that the presence of astemizole in the growth medium increased the anti-proliferative effect of doxorubicin on $\mathrm{H} 295 \mathrm{R}$ cells. In the presence of $0.5 \mu \mathrm{M}$ astemizole, which does not affect cell viability by itself, the $\mathrm{dxr}-\mathrm{IC}_{50}$ decrease was about three times (Figure $3 \mathrm{~A}$ ).

Apoptosis experiments based on caspase 3/7 activation measurements indicated that the addition of astemizole to $\mathrm{dxr}$ treatment increased the number of apoptotic cells in a dose-dependent manner. Indeed, the use of $0.5 \mu \mathrm{M}$ of astemizole, which does not affect caspase $3 / 7$ activity by itself, multiplies it by five the number of apoptotic cells relative to cells treated with $2 \mu \mathrm{M} \mathrm{dxr}$ without astemizole (Figure 3B).

We also observed that the combination of $d x r$ and astemizole significantly inhibited the ability of $\mathrm{H} 295 \mathrm{R}$ cells to form clones at a concentration of $\mathrm{dxr}$ that did not affect it by itself, and increased four times the anti-clonogenic activity of dxr (Figure 3C).

H295R cells form spheres when grown in 3D culture medium. ACC cells were grown in these conditions in the presence of increasing concentrations of $d x r$, astemizole or a combination of $d x r+$ astemizole. Figure 3D shows that the spheroids formed after 14 days were significantly smaller when treated with the combination of $\mathrm{dxr}+$ astemizole, while the concentration of $\mathrm{dxr}$ or astemizole used did not affect spheroid growth by itself.

Our results clearly show that astemizole significantly increased the anti-proliferative, pro-apoptotic and anti-clonogenic effects of $d x r$ against ACC cells. 
A

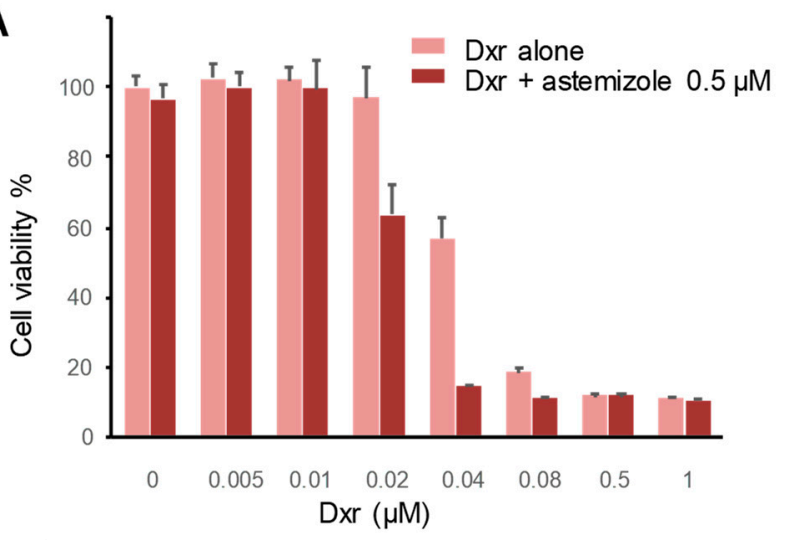

\begin{tabular}{|c|c|}
\hline Astemizole $(\mu \mathrm{M})$ & Dxr $-\mathrm{I}_{50}(\mu \mathrm{M})$ \\
\hline 0 & $0.1 \pm 0.02$ \\
\hline 0.5 & $0.03 \pm 0.01$ \\
\hline
\end{tabular}

B

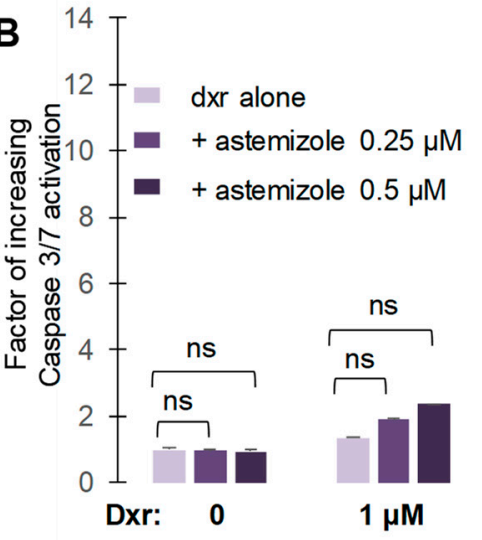

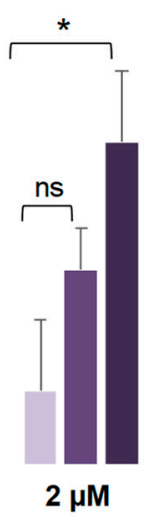

\section{C}
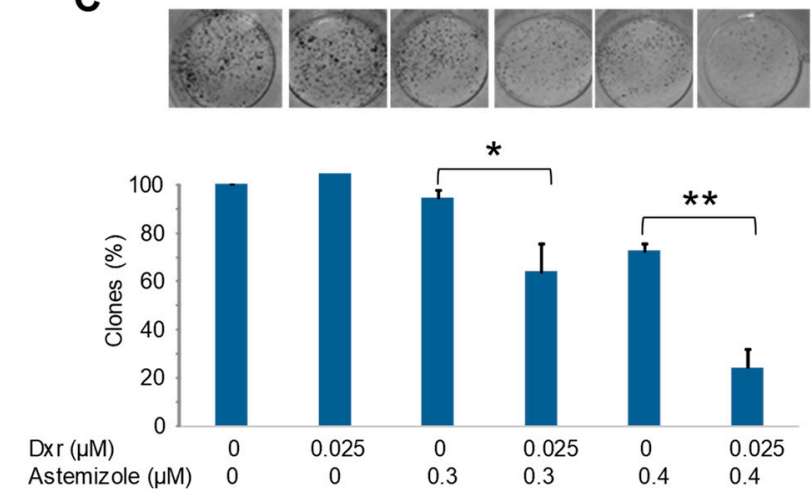

D

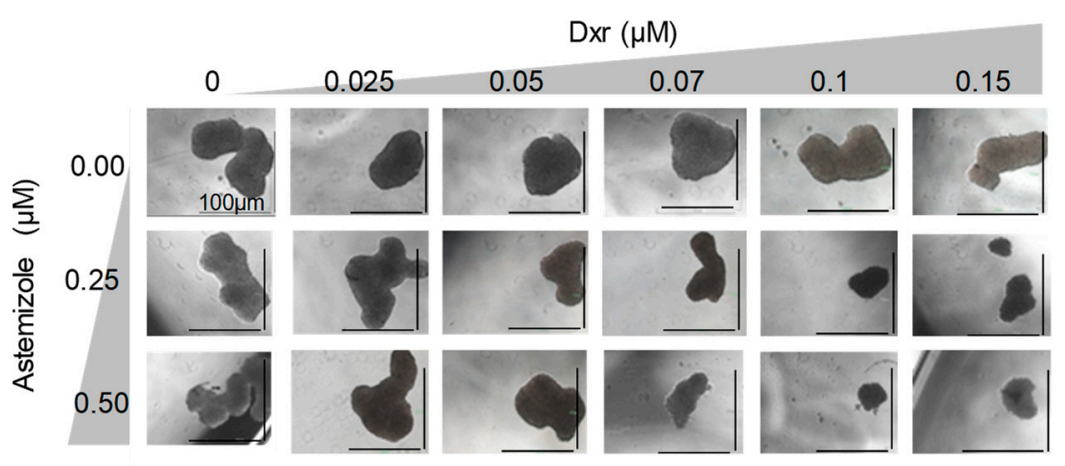

Figure 3. Astemizole increases the anti-proliferative, pro-apoptotic and anti-clonogenic effects of doxorubicin. (A) H295R cells were treated with serial dilutions of dxr with or without astemizole $0.5 \mu \mathrm{M}$ for 7 days. The effect on cell proliferation was quantified using the neutral red assay. Data are represented as mean $\pm \mathrm{SEM}$. $\mathrm{IC}_{50}$ values were calculated from 3 different experiments using the Prism 6 software. (B) Apoptosis was evaluated using the luminescent assay Caspase-Glo 3/7 kit after $48 \mathrm{~h}$ incubation of H295R cells with medium alone or medium containing dxr alone, astemizole alone or a combination of $\mathrm{dxr}$ and astemizole. Caspase activation of cells was reported as a factor of the caspase activity of the control cells treated with DMSO. (C) For the clone formation test, H295R cells were treated with DMSO as a control, $\mathrm{dxr}$ or astemizole alone or a combination of $\mathrm{dxr}$ and astemizole. Clones were revealed with crystal violet solution after 14 days, pictures were taken and absorbance was read at $550 \mathrm{~nm}$ after solubilization. (D) H295R cells were plated in a 3D culture medium and treated with $\mathrm{dxr}$ or astemizole alone, or a combination of dxr and astemizole. After 14 days, pictures were taken using a cell imager. The experiment reported is representative of the 3 experiments performed. Histograms represent the mean \pm SEM of 3 experiments. Data were analyzed using ANOVA multiple comparison test and Bonferroni correction. Significance is attained at $p<0.05\left(^{*}\right)^{(* *} p<0.005$, ns: no significant difference). 


\subsection{Astemizole Inhibits Doxorubicin Efflux from ACC Cells}

We recently showed that the inhibition of Ptch1 expression using siRNA strongly reduced the efflux of dxr from H295R cells revealing that Ptch1 participated in dxr efflux and drug resistance in these cells [13]. We observed that treatment of H295R cells with astemizole for $48 \mathrm{~h}$ had no effects on Ptch1 protein expression (Figure 2C), indicating that the increase in dxr cytotoxicity observed in the presence of astemizole is not due to the inhibition of Ptch1 expression but rather to the inhibition of Ptch1 drug efflux activity.

As exemplified in Figure 4A, incubation of H295R cells with dxr for $2 \mathrm{~h}$ induced a strong accumulation of $d x r$ in the cells. The intracellular $d x r$ amount was drastically reduced after $30 \mathrm{~min}$ in the efflux buffer. Quantification of dxr fluorescence in cells indicated that 60 to $70 \%$ of $d x r$ was transported out of the cells over this period time. Interestingly, the presence of astemizole in the efflux buffer allowed keeping about $73 \%$ of $d x r$ inside the cells. This result demonstrates that astemizole strongly inhibited the efflux of $d x r$ from H295R cells.

A
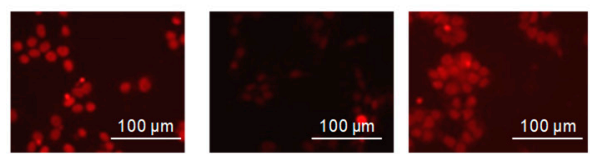

ns

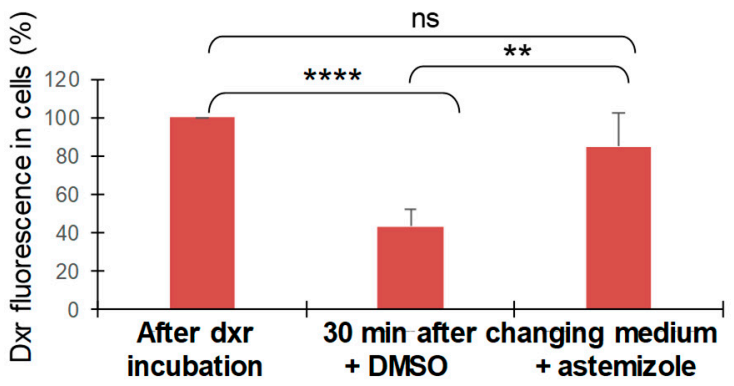

B
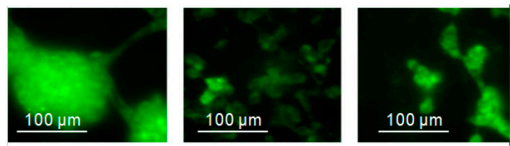

ns

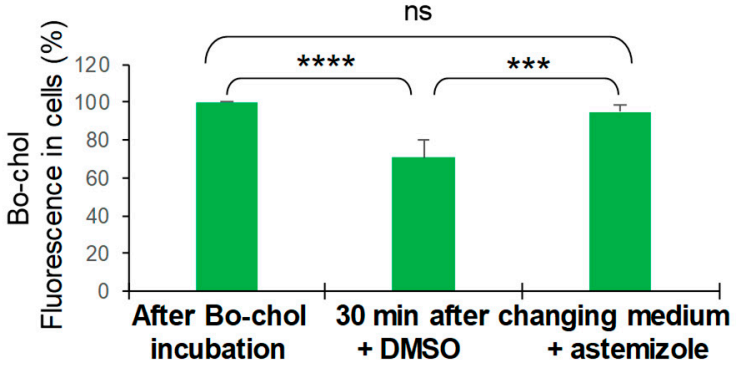

Figure 4. Astemizole inhibits the efflux activity of Ptch1. H295R cells were seeded on coverslips and incubated with dxr (A) or BODIPY-cholesterol (Bo-chol) (B). After $2 \mathrm{~h}, 3$ coverslips were fixed for dxr or Bo-chol loading control. The other coverslips were incubated with DMSO or astemizole for $30 \mathrm{~min}$ and fixed. Images were acquired using fluorescence microscopy and a 40x objective. Fluorescence was quantified using the Image J software for 100 cells per condition. Histograms represent the mean \pm SEM values of 3 independent experiments. Significance, calculated using ANOVA multiple comparison test and Bonferroni correction, was attained at $p<0.05\left(^{*}\right)\left(^{* *}: p<0.005,{ }^{* * *}: p<0.0005,{ }^{* * * *}: p<0.00005\right.$, ns: no significant difference).

Remarkably, we observed that astemizole also inhibits dxr efflux from melanoma cells such as MeWo which endogenously express Ptch1 [20], and increases dxr cytotoxicity in these cells (Sup. Figure 2A,B).

\subsection{Astemizole Inhibits Cholesterol Efflux from ACC Cells}

We have previously shown that Ptch1 regulates Hedgehog signaling by transporting cholesterol out of cells [32]. Thus, we measured the effect of astemizole on the cholesterol efflux in ACC cells. To do so, we used a fluorescent derivative of cholesterol: BODIPY-cholesterol (Bo-chol). As shown in Figure 4B, incubation of cells with Bo-chol induced a strong accumulation of Bo-chol inside the cells. After $30 \mathrm{~min}$ in the efflux buffer, we observed a reduction of $29 \%$ in Bo-chol fluorescence inside the cells, indicating an efflux of Bo-chol. The presence of astemizole in the efflux buffer allowed keeping about $95 \%$ of Bo-chol inside the cells. This result strongly suggests that astemizole also inhibited cholesterol efflux in ACC cells. 


\subsection{Astemizole Binds to Ptch1 in the Same Binding Pocket as Cholesterol and Doxorubicin}

We performed in silico docking on the cryo-EM structure of Ptch1 PDB ID 6N7H [26]. The available structures to date have up to three cavities containing cholesterol. The one we are particularly interested in is the central cavity. This central cavity is not found in all structures, suggesting that it is a dynamic cavity within the transport mechanism of cholesterol. This is supported by the fact that it is constructed between loops, which therefore demonstrates flexibility and ability to accommodate different sized ligands. The presence of numerous aromatic amino acids with polar groups such as tyrosine and tryptophan, as well as polar residues among the hydrophobic ones, also gives the ability to accommodate various ligands and provide a wide range of interactions.

In view of the potential major role of this cavity in Ptch1 efflux activity, we have looked at whether some of the amino acids that compose it can be the cause of pathology in the case of mutation, which would underline their role in the transport of cholesterol. This is the case for eight of them according to the BioMuta database [33] (Table 2, amino acids in bold). If an amino acid is vital to the proper functioning of a protein, one would expect it to be conserved within the family protein. Among those surrounding the cholesterol, five are conserved in the Patched family (between * in Table 2), two of which have side chains directed to the cholesterol (Leu427 and Ala497).

Table 2. List of amino acids within a radius of $6 \AA$ from cholesterol, doxorubicin or astemizole.

\begin{tabular}{|c|c|}
\hline Ligand & Amino Acid Involved \\
\hline Cholesterol & 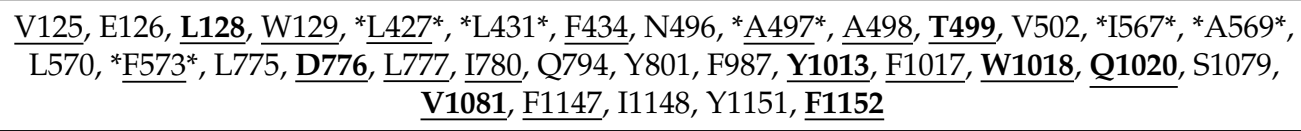 \\
\hline Astemizole & 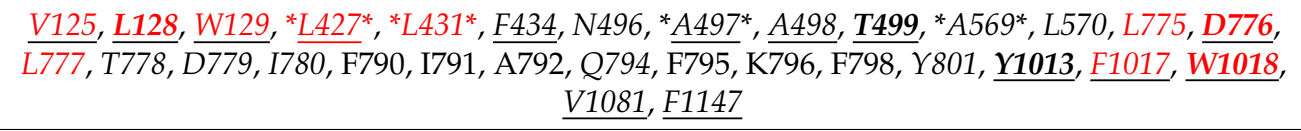 \\
\hline Doxorubicin & $\mathrm{N} 124, \underline{V 125}, \underline{L 128}, \underline{W 129}, \mathrm{~F} 422, \mathrm{~T} 424,{ }^{* \mathrm{~L} 427^{*}},{ }^{*} \mathrm{~L} 431^{*}, \mathrm{G} 774, \mathrm{~L} 775, \underline{\mathrm{D} 776}, \underline{\mathrm{L} 777}, \underline{\mathrm{F} 1017}, \underline{\mathrm{W} 1018}$, \\
\hline
\end{tabular}

All these elements comfort us in carrying out our docking on this cavity specifically. The analysis was performed on the 10 best poses of the docking (ranked by score). Since both the amino acids involved in the interaction with astemizole and the nature of the interactions were similar among those poses, only one pose is presented (Figure 5).

We previously observed that the best docking poses for dxr superimposed on cholesterol, and, very interestingly, we show here that the best docking poses for astemizole superimposed with cholesterol and dxr. As presented in Table 2, 26 amino acids over the 33 surrounding cholesterols and 10 amino acids over the 16 surrounding dxrs in a radius of $6 \AA$ are also in a radius of $6 \AA$ of astemizole (Table 2). Interestingly, three amino acids for which mutations are responsible for diseases, suggesting that they are important for Ptch1 function, are in the surrounding of cholesterol, dxr and astemizole: L128, D776, W1018.

From the 2D representation of the interaction between astemizole and Ptch1, we notice that most of them are hydrophobic interactions (W129, L777, I780, W1018) and one is a pi-stacking type (F1017). With this docking being performed on a rigid structure, it does not unveil all interactions astemizole can have with Ptch1. It is highly possible that the polar atoms of astemizole are engaged in polar interactions such as $\mathrm{H}$ bonds but are not found or represented in this in silico docking. 


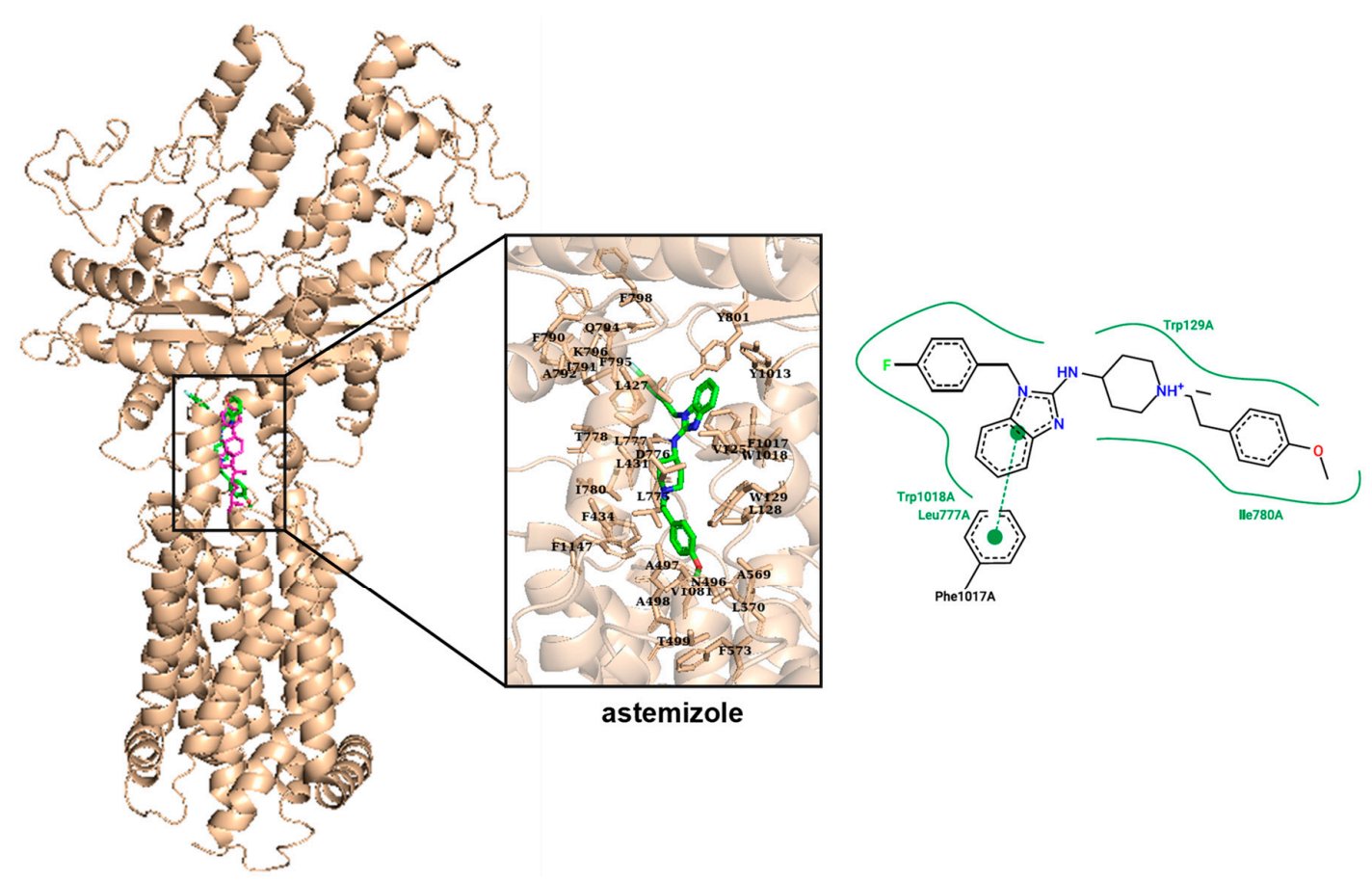

Figure 5. Docking of astemizole in the human Ptch1 protein structure. Chain A from pdb 6n7h is represented on the left. Cholesterol (magenta) and astemizole (green) bind in the same central binding cavity when docked with Vina. Astemizole interacts with similar amino acids as cholesterol (see Table 2). On the right, 2D representation of interactions between astemizole and Ptch1: curved green line represents hydrophobic interactions, and dashed green line represents pi-stacking interactions.

\subsection{Astemizole is Cytotoxic for ACC Cells}

Astemizole has gained great interest as a potential anticancer drug because it targets several proteins involved in cancer including the Eag1 (ether à-go-go-1) potassium channel that is overexpressed in many cancers and is strongly related to carcinogenesis and tumor progression [34,35]. We, therefore, tested the effect of astemizole on H295R cells, and we observed that astemizole was cytotoxic for ACC cells with an $\mathrm{IC}_{50}$ of about $7 \mu \mathrm{M}$ (Figure $6 \mathrm{~A}$ ) and inhibited their proliferation (Figure $6 \mathrm{~B}$ ). A similar effect was observed on melanoma cells, while astemizole only has a very slight effect on keratinocyte viability (Figure S2A,C).
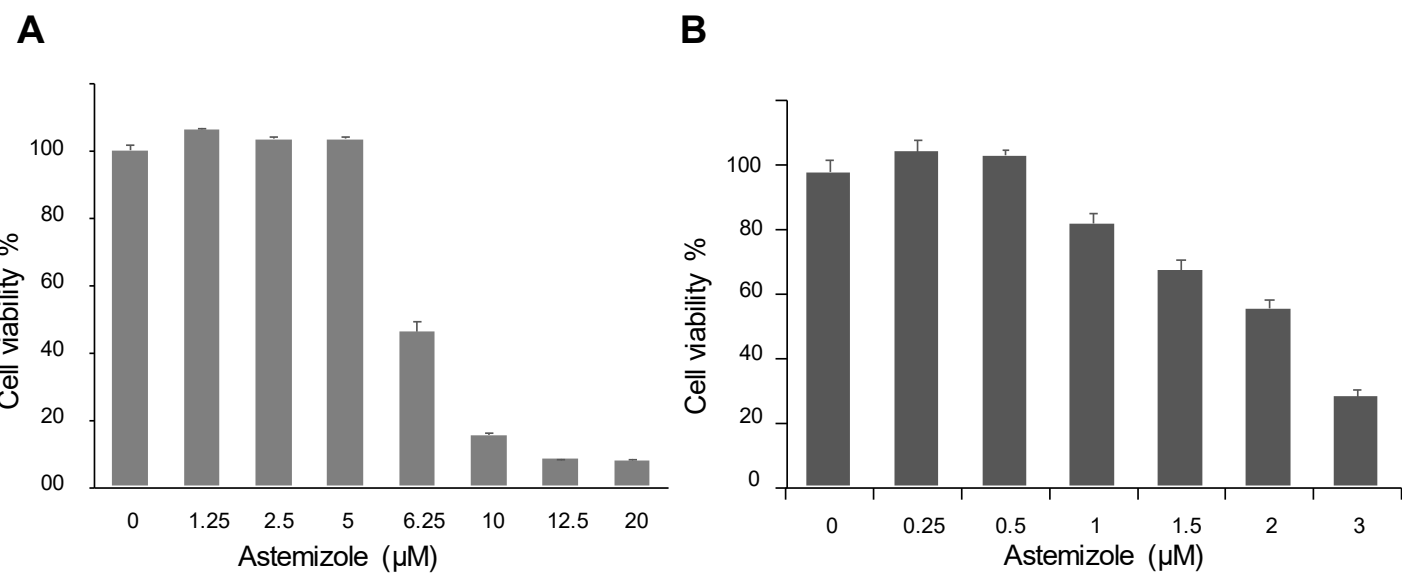

Figure 6. Astemizole has a cytotoxic and anti-proliferative effect on ACC cells. Cell viability was measured after treatment with a serial dilution of astemizole added on $\mathrm{H} 295 \mathrm{R}$ cells at $80 \%$ confluence for $48 \mathrm{~h}$ (A), or added for 7 days when H295R cells were plated (B). The graphs reported are representative of more than 3 repeated experiments. 


\subsection{Astemizole Properties}

Numerous structurally and functionally unrelated drugs block the hERG potassium channel, well known for its role in repolarizing the cardiac action potential. The alteration of hERG by pharmacological inhibition produces long QT syndrome and the lethal cardiac arrhythmia torsade de pointes. Astemizole has been withdrawn from the market because of QT prolongation [35-37]. Therefore, we measured the effect of astemizole on the hERG channel current by electrophysiology. $\mathrm{I}_{\mathrm{hERG}}$ "pulse" amplitude was monitored during repetitive application of the protocol presented in Figure 7 , and we observed that $1 \mu \mathrm{M}$ astemizole induced about a $70 \%$ reduction in $\mathrm{I}_{\mathrm{hERG}}$ pulse amplitude, confirming the ability of astemizole to inhibit the hERG channel.
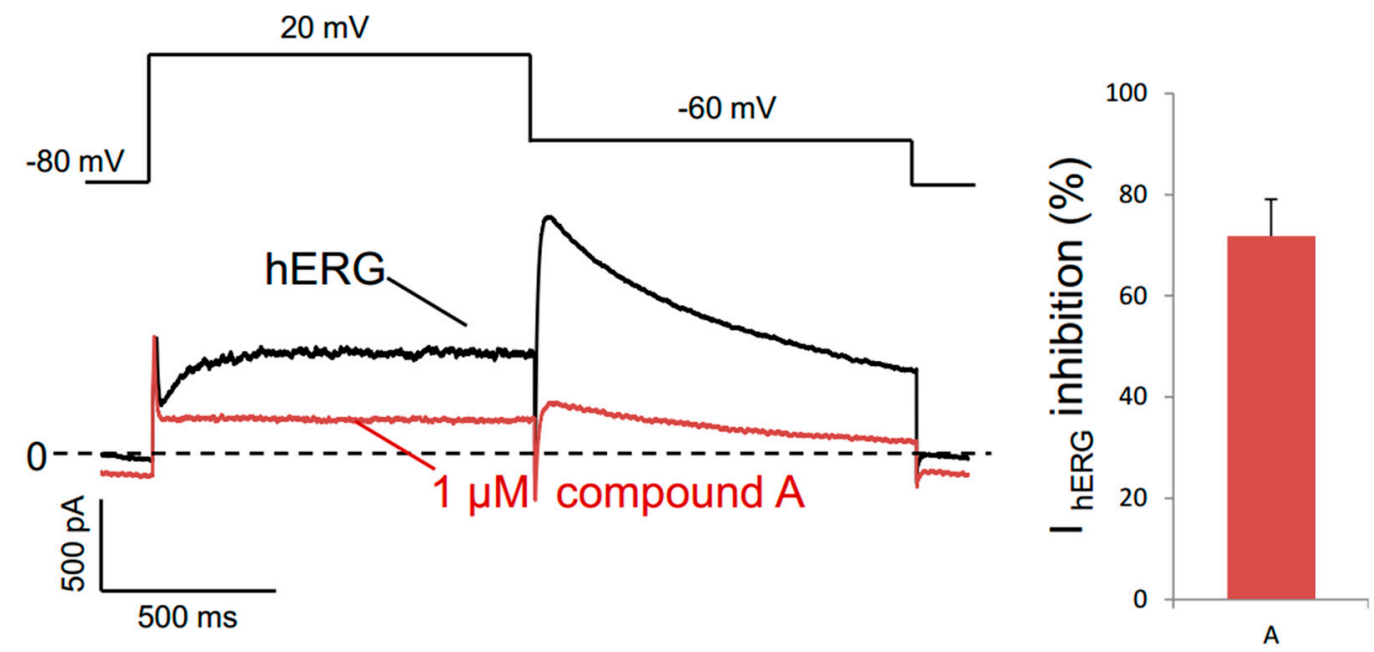

Figure 7. Effect of astemizole on hERG. IhERG "pulse" amplitude was monitored on HEK293 cells overexpressing hERG during repetitive application of the protocol shown in the upper panel. Currents in control (black) and the presence of $1 \mu \mathrm{M}$ astemizole (red) have been recorded. The percentage of reduction in $\mathrm{I}_{\mathrm{hERG}}$ pulse amplitude induced by $1 \mu \mathrm{M}$ astemizole is reported.

We also performed an ADME analysis on astemizole (Table 3). We determined its lipophilicity described by the distribution constant $\log \mathrm{D}$, its solubility, which is an important parameter since water is the solvent of choice for the liquid pharmaceutical formulation, its metabolic stability measured in the presence of rat and human microsomes and NADPH, and its ability to bind to proteins. Results showed that astemizole is metabolically stable and possesses lipophilicity and solubility properties compatible with a drug candidate.

Table 3. Profiling data for astemizole.

\begin{tabular}{ccccccc}
\hline LogD7.4 & $\begin{array}{c}\text { Aqueous } \\
\text { Solubility }(\mu \mathrm{M})\end{array}$ & $\begin{array}{c}\text { RLM T1/2 } \\
(\mathrm{min})\end{array}$ & $\begin{array}{c}\text { RLM } \\
(\mu \mathrm{L} / \mathrm{min} / \mathrm{mg})\end{array}$ & $\begin{array}{c}\text { HLM T1/2 } \\
(\mathbf{m i n})\end{array}$ & $\begin{array}{c}\text { HLM } \\
(\mu \mathrm{L} / \mathrm{min} / \mathrm{mg})\end{array}$ & Ppb (\%) \\
\hline 3.5 & 22.1 & 31 & $<115.5$ & $>60$ & $<115.5$ & 99 \\
\hline
\end{tabular}

The distribution coefficient between octanol and phosphate buffer saline (PBS) measured at pH 7.4 (Log D 7.4), the solubility in aqueous buffer (PBS, pH 7.4) and propylene glycol (PG), the chemical stability in aqueous solution (PBS, pH 7.4) and PG over 7 days, the metabolic stability in human and rat liver microsomes (HLM and RLM, respectively) and the human plasma protein binding (ppb \%) are reported.

\section{Discussion}

In this study, we report that astemizole inhibited doxorubicin efflux in hPtch1-expressing yeast and alleviated resistance to dxr conferred by hPtch1 to yeast, while it had no effects on control yeast (Figure 1). In silico docking showed that the best poses for astemizole were in the central cholesterol-binding pocket of Ptch1, where we also found the best poses for doxorubicin (Figure 5, 
Table 2). These results suggest that astemizole could inhibit the efflux activity of the Hh receptor Ptch1 by direct binding to the Ptch1 protein.

We previously reported that Ptch1 is expressed in ACC and contributes to the resistance of these tumors to treatment [13]. We then tested astemizole on ACC cells and observed that this molecule, at a concentration that does not affect by itself, significantly increased the cytotoxic, pro-apoptotic, anti-proliferative and anti-clonogenic effects of doxorubicin, which is one of the chemotherapeutic agents of the standard treatment for ACC patients (Figures 2 and 3). Our experiments revealed that astemizole was able to inhibit dxr efflux in ACC cells (Figure 5), in good agreement with results obtained in hPtch1-expressing yeast, explaining that astemizole increased dxr efficacy against ACC cells. Our results also showed that astemizole inhibited cholesterol efflux, which is the physiological activity of Ptch1. These results together with data obtained from hPtch1-expressing yeast and in silico docking strongly suggest that astemizole increased the sensitivity to doxorubicin of yeast and ACC cells by inhibiting the dxr efflux activity of Ptch1 and that Ptch1 is a new target of astemizole.

These data are in good agreement with previous studies reporting that when administrated in combination with a chemotherapeutic treatment, astemizole has shown a significant association with reduced mortality among cancer patients. One of the explanations given is that astemizole sensitizes cancer cells to chemotherapy and reverts multidrug resistance [38]. In vitro and preclinical studies suggest that astemizole may act synergistically in combination with chemotherapeutic agents. Indeed, astemizole was shown to synergistically potentiate the cytotoxicity of doxorubicin against doxorubicin-resistant human leukemia cells [39], and of gefitinib against human lung cancer [34]. This was attributed to an effect of astemizole on several proteins involved in cancer progression such as histamine receptors, ABC transporters and the potassium channels Eag1 and hERG [40]. However, our study suggests that these effects could also be due to the inhibition of the drug efflux activity of Ptch1 which is known to be expressed in many cancers (see [15] for review and the Human Protein Atlas website http://www.proteinatlas.org/ENSG00000185920-PTCH1/cancer). Astemizole is a second-generation $\mathrm{H}_{1}$ antihistamine drug approved in 1986 for the treatment of allergic rhinitis and conjunctivitis. It has a high affinity for the histamine $\mathrm{H}_{1}$ receptor, but also for the potassium channels Eag1 and hERG, as we have also reported in Figure 7, inducing serious adverse cardiac reactions. Accordingly, it was withdrawn from the market in 1999 for safety-related reasons [36]. Moreover, in vitro and nonclinical in vivo studies suggested that astemizole had anticancer properties by inhibiting the hERG channel and/or cytochrome CYP2J2, both of which being upregulated and overexpressed in various cancers [41]. We observed that astemizole also has a cytotoxic effect in ACC cells with an $\mathrm{IC}_{50}$ of about $7 \mu \mathrm{M}$ (Figure 6), although overexpression of CYP2J2 or hERG in ACC has not been reported to date. We also observed that astemizole is cytotoxic on melanoma cells with an $\mathrm{IC}_{50}$ of about $7 \mu \mathrm{M}$, while its cytotoxicity is much lower with respect to non-tumorigenic keratinocytes (Sup. Figure 2). It is interesting to note that the concentration of astemizole shown to increase cytotoxicity and the anti-proliferative effects of doxorubicin ( 1 and $0.5 \mu \mathrm{M}$, respectively) have no effects in the absence of $\mathrm{dxr}$ (Figures 2, 3 and 6), indicating that astemizole acts synergistically in combination with $\mathrm{dxr}$ as already reported. This suggests that, at these low concentrations, astemizole acts only on Ptch1 drug efflux activity in these cells. We are currently working on the chemical modification of astemizole to make it lose its affinity for hERG. The optimized compound obtained will be tested on mice grafted with ACC cells to evaluate in vivo activity of this lead. The use of a combination of doxorubicin with a derivative of astemizole able to interact with Ptch1 but not with hERG would be a promising therapeutic option for ACC.

Our study provides strong evidence that astemizole is an inhibitor of the efflux activity of the Hedgehog receptor Ptch1, and that the synergistic effect of astemizole, when combined with chemotherapeutic agents such as doxorubicin, could also be related to the inhibition of Ptch1 drug efflux activity. Our results suggest that the use of a low dose of astemizole with no adverse effects by itself or of an astemizole derivative able to interact with Ptch1 but not with hERG could improve the effectiveness of the standard of care treatment for ACC patients, and could be a promising therapeutic option. 
Supplementary Materials: Supplementary materials can be found at http://www.mdpi.com/2227-9059/8/8/251/s1.

Author Contributions: Conception and design, I.M.-V.; development of methodology, M.S., F.S.C. and I.M.-V.; acquisition of data, A.H., M.S. and F.S.C.; analysis and interpretation of data, A.H., M.S., F.S.C. and I.M.-V.; writing-original draft, I.M.-V.; writing-review and editing, A.H., M.S., E.L. and I.M.-V.; funding acquisition, I.M.-V. and E.L.; resources, I.M.-V. and E.L.; supervision, I.M.-V. All authors have read and agreed to the published version of the manuscript.

Funding: This research was funded by grants from Centre National de la Recherche Scientifique (CNRS) through the "Soutien au transfert" program, Association France Cancer, Région Provence Alpes Côte d'Azur through the APRF program (2013-17362), Canceropôle PACA, and French National Research Agency (ANR) through the Investments for the Future UCA ${ }^{\mathrm{JEDI}}$ [ANR-15-IDEX-01] to I.M-V., from French National Research Agency (ANR) through the «Investments for the Future » LABEX SIGNALIFE program [ANR-11-LABX-0028-01] to E.L. and A.H. APC was funded by [ANR-15-IDEX-01].

Acknowledgments: We thank Dominique Douguet and Valérie Biou for helpful discussions.

Conflicts of Interest: The authors declare no competing interests. The funders had no role in the design of the study; in the collection, analyses, or interpretation of data; in the writing of the manuscript, or in the decision to publish the results.

\section{References}

1. Fassnacht, M.; Allolio, B. Clinical management of adrenocortical carcinoma. Best Pract. Res. Clin. Endocrinol. Metab. 2009, 23, 273-289. [CrossRef]

2. Kebebew, E.; Reiff, E.; Duh, Q.Y.; Clark, O.H.; McMillan, A. Extent of disease at presentation and outcome for adrenocortical carcinoma: Have we made progress? World J. Surg. 2006, 30, 872-878. [CrossRef] [PubMed]

3. Bertherat, J.; Arlt, W.; Beuschlein, F.; Chanson, P.; Mantero, F.; Plouin, P.F. Adrenal tumours and hormone excess. Editorial. Ann. Endocrinol. (Paris) 2009, 70, 147. [CrossRef] [PubMed]

4. Sinclair, T.J.; Gillis, A.; Alobuia, W.M.; Wild, H.; Kebebew, E. Surgery for adrenocortical carcinoma: When and how? Best Pract. Res. Clin. Endocrinol. Metab. 2020, 3, 101408. [CrossRef] [PubMed]

5. Lalli, E.; Luconi, M. The next step: Mechanisms driving adrenocortical carcinoma metastasis. Endocr. Relat. Cancer 2018, 25, R31-R48. [CrossRef]

6. Fassnacht, M.; Terzolo, M.; Allolio, B.; Baudin, E.; Haak, H.; Berruti, A.; Welin, S.; Schade-Brittinger, C.; Lacroix, A.; Jarzab, B.; et al. Combination chemotherapy in advanced adrenocortical carcinoma. N. Engl. J. Med. 2012, 366, 2189-2197. [CrossRef]

7. Baudin, E.; Pellegriti, G.; Bonnay, M.; Penfornis, A.; Laplanche, A.; Vassal, G.; Schlumberger, M. Impact of monitoring plasma 1,1-dichlorodiphenildichloroethane (o,p'DDD) levels on the treatment of patients with adrenocortical carcinoma. Cancer 2001, 92, 1385-1392. [CrossRef]

8. Haak, H.R.; Hermans, J.; van de Velde, C.J.; Lentjes, E.G.; Goslings, B.M.; Fleuren, G.J.; Krans, H.M. Optimal treatment of adrenocortical carcinoma with mitotane: Results in a consecutive series of 96 patients. Br. J. Cancer 1994, 69, 947-951. [CrossRef]

9. Fassnacht, M.; Libé, R.; Kroiss, M.; Allolio, B. Adrenocortical carcinoma: A clinician's update. Nat. Rev. Endocrinol. 2011, 7, 323-335. [CrossRef]

10. Luqmani, Y.A. Mechanisms of drug resistance in cancer chemotherapy. Med. Princ. Pract. 2005, 14, 35-48. [CrossRef]

11. Queiroz, K.C.; Ruela-de-Sousa, R.R.; Fuhler, G.M.; Aberson, H.L.; Ferreira, C.V.; Peppelenbosch, M.P.; Spek, C.A. Hedgehog signaling maintains chemoresistance in myeloid leukemic cells. Oncogene 2010, 29, 6314-6322. [CrossRef] [PubMed]

12. Saze, Z.; Terashima, M.; Kogure, M.; Ohsuka, F.; Suzuki, H.; Gotoh, M. Activation of the sonic hedgehog pathway and its prognostic impact in patients with gastric cancer. Dig Surg. 2012, 29, 115-123. [CrossRef] [PubMed]

13. Hasanovic, A.; Ruggiero, C.; Jung, S.; Rapa, I.; Signetti, L.; Hadj, M.B.; Terzolo, M.; Beuschlein, F.; Volante, M.; Hantel, C.; et al. Targeting the multidrug transporter Patched potentiates chemotherapy efficiency on adrenocortical carcinoma in vitro and in vivo. Int. J. Cancer 2018, 143, 199-211. [CrossRef]

14. Bidet, M.; Tomico, A.; Martin, P.; Guizouarn, H.; Mollat, P.; Mus-Veteau, I. The Hedgehog receptor Patched functions in multidrug transport and chemotherapy resistance. Mol. Cancer Res. 2012, 10, 1496-1508. [CrossRef] 
15. Hasanovic, A.; Mus-Veteau, I. Targeting the Multidrug Transporter Ptch1 Potentiates Chemotherapy Efficiency. Cells 2018, 7, 107. [CrossRef] [PubMed]

16. Taylor, S.; Spugnini, E.P.; Assaraf, Y.G.; Azzarito, T.; Rauch, C.; Fais, S. Microenvironment acidity as a major determinant of tumor chemoresistance: Proton pump inhibitors (PPIs) as a novel therapeutic approach. Drug Resist. Updates 2015, 23, 69-78. [CrossRef] [PubMed]

17. Damaghi, M.; Wojtkowiak, J.W.; Gillies, R.J. pH sensing and regulation in cancer. Front. Physiol. 2013, 17, 370. [CrossRef]

18. Fiorini, L.; Mus-Veteau, I. Method to Screen Multidrug Transport Inhibitors Using Yeast Overexpressing a Human MDR Transporter. Methods Mol. Biol. 2016, 1432, 303-318.

19. Fiorini, L.; Tribalat, M.-A.; Sauvard, L.; Cazareth, J.; Lalli, E.; Broutin, I.; Thomas, O.P.; Mus-Veteau, I. Natural paniceins from Mediterranean sponge inhibit the multidrug resistance activity of Patched and increase chemotherapy efficiency on melanoma cells. Oncotarget 2015, 6, 22282-22287. [CrossRef]

20. Signetti, L.; Elizarov, N.; Simsir, M.; Paquet, A.; Douguet, D.; Labbal, F.; Debayle, D.; Di Giorgio, A.; Biou, V.; Girard, C.; et al. Inhibition of Patched Drug Efflux Increases Vemurafenib Effectiveness against Resistant BrafV600E Melanoma. Cancers (Basel) 2020, 12, 1500. [CrossRef]

21. Kroiss, M.; Sbiera, S.; Kendl, S.; Kurlbaum, M.; Fassnacht, M. Drug Synergism of Proteasome Inhibitors and Mitotane by Complementary Activation of ER Stress in Adrenocortical Carcinoma Cells. Horm. Cancer 2016, 7, 345-355. [CrossRef] [PubMed]

22. Chou, T.C. Theoretical basis, experimental design, and computerized simulation of synergism and antagonism in drug combination studies. Pharmacol. Rev. 2006, 58, 621-681. [CrossRef] [PubMed]

23. Choveau, F.S.; El Harchi, A.; Rodriguez, N.; Louérat-Oriou, B.; Baró, I.; Demolombe, S.; Charpentier, F.; Loussouarn, G. Transfer of rolf S3-S4 linker to HERG eliminates activation gating but spares inactivation. Biophys. J. 2009, 97, 1323-1334. [CrossRef] [PubMed]

24. Trott, O.; Olson, A.J. AutoDock Vina: Improving the speed and accuracy of docking with a new scoring function, efficient optimization and multithreading. J. Comput. Chem. 2010, 31, 455-461. [CrossRef]

25. Pettersen, E.F.; Goddard, T.D.; Huang, C.C.; Couch, G.S.; Greenblatt, D.M.; Meng, E.C.; Ferrin, T.E. UCSF Chimera-A visualization system for exploratory research and analysis. J. Comput. Chem. 2004, 25, 1605-1612. [CrossRef]

26. Qian, H.; Cao, P.; Hu, M.; Gao, S.; Yan, N.; Gong, X. Inhibition of tetrameric Patched1 by Sonic Hedgehog through an asymmetric paradigm. Nat. Commun. 2019, 10, 2320. [CrossRef]

27. Shapovalov, M.V.; Dunbrack, R.L., Jr. A smoothed backbone-dependent rotamer library for proteins derived from adaptive kernel density estimates and regressions. Structure 2011, 19, 844-858. [CrossRef]

28. Wang, J.; Wang, W.; Kollman, P.A.; Case, D.A. Automatic atom type and bond type perception in molecular mechanical calculations. J. Mol. Graph. Model. 2006, 25, 247-260. [CrossRef]

29. Stierand, K.; Maass, P.C.; Rarey, M. Molecular Complexes at a Glance: Automated Generation of two-dimensional Complex Diagrams. Bioinformatics 2006, 22, 1710-1716. [CrossRef]

30. Fährrolfes, R.; Bietz, S.; Flachsenberg, F.; Meyder, A.; Nittinger, E.; Otto, T.; Volkamer, A.; Rarey, M. Proteins Plus: A web portal for structure analysis of macromolecules. Nucleic Acids Res. 2017, 45, W337-W343. [CrossRef]

31. Chang, J.M.; Di Tommaso, P.; Taly, J.F.; Notredame, C. Accurate multiple sequence alignment of transmembrane proteins with PSI-Coffee. BMC Bioinform. 2012, 13, S1. [CrossRef] [PubMed]

32. Bidet, M.; Joubert, O.; Lacombe, B.; Nehmé, R.; Mollat, P.; Brétillon, L.; Faure, H.; Bittman, R.; Ruat, M.; Mus-Veteau, I. The Hedgehog Receptor Patched Contributes to Cholesterol Efflux. PLoS ONE 2011, 6, e23834. [CrossRef] [PubMed]

33. Dingerdissen, H.M.; Torcivia-Rodriguez, J.; Hu, Y.; Chang, T.C.; Mazumder, R.; Kahsay, R. BioMuta and BioXpress: Mutation and expression knowledgebases for cancer biomarker discovery. Nucleic Acids Res. 2018, 46, D1128-D1136. [CrossRef] [PubMed]

34. Chávez-López, M.G.; Zúñiga-García, V.; Hernández-Gallegos, E.; Vera, E.; Chasiquiza-Anchatuña, C.A.; Viteri-Yánez, M.; Sanchez-Ramos, J.; Garrido, E.; Camacho, J. The combination astemizole-gefitinib as a potential therapy for human lung cancer. Onco Targets Ther. 2017, 10, 5795-5803. [CrossRef] 
35. García-Quiroz, J.; González-González, M.E.; Díaz, L.; Ordaz-Rosado, D.; Segovia-Mendoza, M.; Prado-García, H.; Larrea, F.; García-Becerra, R. Astemizole, an inhibitor of ether-à-go-go-1 potassium channel, increases the activity of the tyrosine kinase inhibitor gefitinib in breast cancer cells. Rev. Invest. Clin. 2019, 71, 186-194. [CrossRef]

36. Du, L.; Li, M.; You, Q.; Xia, L. A novel structure-based virtual screening model for the hERG channel blockers. Biochem. Biophys. Res. Commun. 2007, 355, 889-894. [CrossRef]

37. Zhou, Z.; Vorperian, V.R.; Gong, Q.; Zhang, S.; January, G.T. Block of HERG Potassium Channels by the Antihistamine Astemizole and its Metabolites Desmethylastemizole and Norastemizole. J. Cardiovasc. Electrophysiol. 1999, 10, 836-843. [CrossRef]

38. Ellegaard, A.M.; Dehlendorff, C.; Vind, A.C.; Anand, A.; Cederkvist, L.; Petersen, N.H.; Nylandsted, J.; Stenvang, J.; Mellemgaard, A.; Østerlind, K.; et al. Repurposing cationic amphiphilic antihistamines for cancer treatment. EBioMedicine 2016, 9, 130-139. [CrossRef]

39. Ishikawa, M.; Fujita, R.; Takayanagi, M.; Takayanagi, Y.; Sasaki, K. Reversal of acquired resistance to doxorubicin in K562 human leukemia cells by astemizole. Biol. Pharm. Bull. 2000, 23, 112-115. [CrossRef]

40. Jehle, J.; Schweizer, P.A.; Katus, H.A.; Thomas, D. Novel roles for hERG K (+) channels in cell proliferation and apoptosis. Cell Death Dis. 2011, 2, e193. [CrossRef]

41. Shah, R.R.; Stonier, P.D. Repurposing old drugs in oncology: Opportunities with clinical and regulatory challenges ahead. J. Clin. Pharm. Ther. 2019, 44, 6-22. [CrossRef] [PubMed]

(C) 2020 by the authors. Licensee MDPI, Basel, Switzerland. This article is an open access article distributed under the terms and conditions of the Creative Commons Attribution (CC BY) license (http://creativecommons.org/licenses/by/4.0/). 